\title{
REVIEW
}

\section{Hormonal regulation of male germ cell development}

\author{
Saleela M Ruwanpura, Robert I McLachlan and Sarah J Meachem \\ Prince Henry's Institute of Medical Research, Clayton, Victoria 3168, Australia \\ (Correspondence should be addressed to S J Meachem; Email: sarah.meachem@princehenrys.org)
}

\begin{abstract}
Over the past five decades, intense research using various animal models, innovative technologies notably genetically modified mice and wider use of stereological methods, unique agents to modulate hormones, genomic and proteomic techniques, have identified the cellular sites of spermatogenesis, that are regulated by FSH and testosterone. It has

been established that testosterone is essential for spermatogenesis, and also FSH plays a valuable role. Therefore understanding the basic mechanisms by which hormones govern germ cell progression are important steps towards improved understating of fertility regulation in health diseases.

Journal of Endocrinology (2010) 205, 117-131
\end{abstract}

\section{Introduction}

The past decade has been a critical period in our discoveries of how the complex process of spermatogenic cell development is regulated. These discoveries have been aided through the use of innovative technologies, most notably genetically modified mice, the wider use of best practice stereological methods that allow the rigorous mapping of cell populations, unique agents to modulate hormones, and the genomic and proteomic revolution. Most data come from rodent models, although data are emerging from humans, and similarities in basic processes between species are evidenced. It has been firmly established in rodent models since the 1970s that testosterone is essential for spermatogenesis. The data over the last decade prove that FSH also plays a valuable role, even though it was previously debated. The future challenges for germ cell biologists are to determine the causes and to develop strategies to address the common problem of male infertility. Herein, we aim to provide an overview of male germ cell regulation with relevance to clinical disorders of fertility.

Germ cell development involves mitotic and meiotic divisions and the commitment to 'differentiate or die (survive)' in a process requiring master regulators, $\mathrm{FSH}$ and testosterone. FSH and testosterone act at multiple sites in spermatogenesis, either alone or in concert. In rodents, FSH predominantly supports spermatogonial development, while it appears that testosterone provides little support (reviewed in McLachlan et al. (2002a) and Ruwanpura et al. $(2008 a, b))$. Testosterone partly supports spermatocyte maturation; however, it is critical (at least in rats) in facilitating round to elongated spermatid progression. The release of spermatids from Sertoli cells (termed spermiation) requires both testosterone and FSH (reviewed in McLachlan et al. (2002a)). In humans, spermatogonial development, meiosis, and spermiation are the three main processes that are regulated by gonadotrophins (McLachlan et al. 2002b, Matthiesson et al. 2005, 2006).

A stable germ cell population is determined by the balance of death (apoptosis) and division, which are influenced by many biochemical factors. The highly coordinated nature of spermatogenesis requires intimate functional and junctional communications between Sertoli and germ cells (Kierszenbaum \& Tres 2004, reviewed in Mruk \& Cheng (2004) and Sluka et al. (2006)). It is generally accepted that germ cells do not contain receptors for hormones; thus, these endocrine factors exert their biological effects on spermatogenesis via the receptors located in or on the plasma membrane of Sertoli cells (Parvinen 1982). Sperm output relies on the establishment of a normal adult Sertoli cell population, which is set around puberty in mammals (for rodents around 2 weeks after birth; Orth 1984, Orth et al. 1988, for humans 11-13 years; Zivkovic \& Hadziselimovic 2009). Prior to puberty, there is an early wave of spermatogonial apoptosis (effecting 70\% of spermatogonial death), which is required to maintain a critical ratio between germ and Sertoli cells (Rodriguez et al. 1997). However, it is considered that the Sertoli cell population may not tightly regulate germ cell populations in the testis as originally thought, as transplantation of rat germ cells into the testis of an infertile mouse has shown that germ cells, not Sertoli cells, control the timing and organization of spermatogenesis (Franca et al. 1998).

New findings show that hormones, predominantly FSH and testosterone, act as survival factors to regulate 
pathway-specific apoptotic genes and proteins, rather than proliferation (Nandi et al. 1999, Woolveridge et al. 1999, Chausiaux et al. 2008, Ruwanpura et al. 2008a,b). The intrinsic (mitochondrial) and extrinsic (death receptor) apoptotic pathways play roles in executing germ cell death, although as yet other pathways are unexplored: in the case of spermatogonia, this appears to be almost exclusively via the intrinsic apoptotic pathway in FSH-suppressed rodents (Ruwanpura et al. 2008a,b) and in gonadotrophin-deficient men (Ruwanpura et al. 2008c). While testosterone regulates rodent spermatocyte and spermatid survival via both the intrinsic and extrinsic pathways (Ross et al. 1998, Nandi et al. 1999, Woolveridge et al. 1999, Chausiaux et al. 2008). Understanding these mechanisms may provide new approaches to the development of therapeutic interventions for infertility.

\section{Mechanisms of germ cell survival}

There are 11 different types of cell survival mechanisms that are known; 10 of which proceed according to genetically programmed mechanisms, while necrosis is the only non-genetically programmed cell death mechanism which occurs in pathological conditions (Melino et al. 2005). However, only three of the genetically programmed cell death mechanisms, such as caspase-dependent apoptosis (Sinha-Hikim \& Swerdloff 1999, Shaha 2007), anoikis (Show et al. 2004), and caspase-independent apoptosis (Lockshin \& Zakeri 2004), are described in the testis. Caspase-dependent apoptosis (hereafter referred to as 'apoptosis') is the most common and is distinct from other forms of cell death due to its involvement in caspase activation via pathways employing death receptors and/or BCL2 family regulators. Apoptosis has been defined morphologically, but it is now clear that other forms of death also feature one or more hallmarks of the apoptotic morphological process. Apoptosis has gained intense attention due to its disturbances in a range of human testicular pathologies, such as cancer (reviewed in Mayer et al. (2003)). During normal spermatogenesis, apoptosis regulates the homeostasis of Sertoli cells to germ cell number by inducing programmed cell death to eliminate germ cells that fail to replicate their DNA accurately during cell division. Apoptosis can be also induced by specific stimuli, such as deprivation of hormones, exposure to ionizing radiation, various chemotherapeutic drugs, cell injury, and cell stress.

\section{Biochemical and molecular mechanisms of apoptosis}

In the testis, apoptosis represents molecules-directed mechanism involving cysteine proteases (termed caspases) apoptosis promoters, and adaptors to govern cell death at least via two major pathways (Fig. 1). There are two classes of apoptotic caspases, initiator and executioner caspases, depending on their position of entry into the apoptosis cascade. The initiator caspases, caspases 8, 9, 10, and 12, are the first to get activated in the apoptotic pathway, and then they are involved in the activation of executioner caspases, caspases 3 , 6, and 7, in the latter part of the apoptotic pathway (Fig. 1). Caspases are synthesized as inactive pro-enzymes (procaspases) of $32-56 \mathrm{kDa}$ length (reviewed in Shi (2002)), and they reside in the mitochondrial membrane space or in the endoplasmic reticulum (ER; caspase 12) and are then released into the cytosol for activation. Thereafter, activated caspases translocate to the nucleus to perform the cleavage of other proteins and DNA degradation (Krajewski et al. 1999).

It is important to recognize that not all of the known caspases are cleaved in every cell in response to the same apoptotic stimuli or within a single cell type in response to different apoptotic stimuli. This heterogeneity likely reflects differential activation of caspases within differing cell types for different apoptotic stimuli. The caspase activation of target cells in the testis is triggered via two major pathways, either by intracellular signals resulting in DNA damage (intrinsic pathway) or by a specific signal delivered through cell surface 'death' receptors (extrinsic pathway; Fig. 1).

\section{The intrinsic (mitochondrial) pathway}

The intrinsic pathway involves members of BCL2 family proteins that control the release of cytochrome $C$ from the mitochondria into the cytosol (Fig. 1). In normal cells, BCL2 family proteins are found in the outer membrane of the mitochondria, and are bound to adaptor protein APAF1 (Zou et al. 1997). BCL2L2 (formerly BCLW) is an important pro-survival member of the BCL2 family (Print et al. 1998, Ross et al. 1998) that participates in the regulation of apoptosis by dimerizing with the pro-apoptotic factor BAX (Yan et al. 2000). It is generally held that the ratio of proapoptotic to pro-survival BCL2 family proteins is the critical determinant of cell fate. For example, an excess of BCL2L2 results in cell survival, while an excess of BAX results in cell death via this pathway (Sinha-Hikim \& Swerdloff 1999). Apoptotic signals have been suggested to be involved in the modulation of antioxidant defenses, resulting in increased sensitivity to the reactive oxygen species and the induction of the mitochondrial permeability transition (Erkkila et al. 1999). In turn, this causes the release of cytochrome $C$ into the cytosol and excess BAX to enter into the mitochondria through the open pores of the membrane (reviewed in Adams \& Cory (1998), Ashkenazi \& Dixit (1998) and Green (2000)). The procaspase 9 and APAF1, together with cytochrome $C$, trigger the activation of caspase 9 , and this in turn activates executioner caspases 3, 6, and 7. The activated executioner caspases are involved in the cleavage of intracellular proteins such as poly(ADP-ribose) polymerase, lamin, actin, and gelsolin, resulting in apoptosis (reviewed in Adams \& Cory (1998), Ashkenazi \& Dixit (1998) and Green (2000)). 


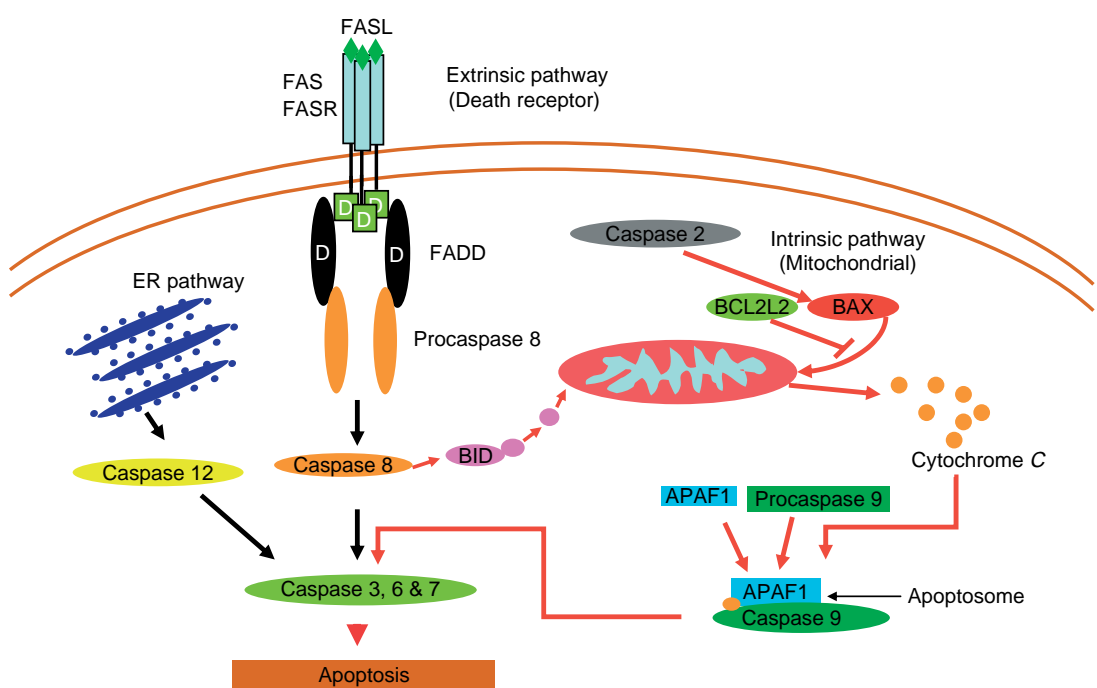

Figure 1 A simplified schematic diagram of the caspase-dependent apoptotic pathway involved in mammalian testicular cells describing three main molecular mechanisms: intrinsic (mitochondrial), extrinsic (death receptor), and endoplasmic reticulum (ER) pathways. The intrinsic pathway involves the translocation of apoptotic inducer BAX (BCL2 family member) into mitochondria, while BCL2L2 acts as a suppressor of cell death. Upon BAX translocation, cytochrome $C$ is released into the cytosol where it binds to the apoptosis protease activating factor-1 (APAF1). APAF1 and cytochrome $C$ then bind to procaspase 9 to form an apoptosome by activating caspase 9 , leading to subsequent proteolytic activation of the executioner caspases 3,6, and 7, resulting in apoptosis. Caspase 2 has also been shown to activate this pathway by acting on BAX. The extrinsic pathway involves ligation of death receptor protein, FAS, to its ligand (FASL). Binding of FAS to FASL induces trimerization of FAS receptor (FASR), which recruits FAS-associated death domain (FADD). The FAS-FADD complex binds to the initiator caspase 8 for activation, which then activates the executioner caspases 3, 6, and 7 causing apoptosis. The ER pathway involves the activation of caspase 12 and subsequent activation of executioner caspases. The crosstalk between these pathways occurs at multiple levels. Crosstalk between apoptotic pathways is evidenced by the fact that in some cells, activated caspase 8 leads to a cleavage of the BCL2 protein family member BID. BID can then induce BAX-mediated release of cytochrome $C$ from mitochondria, further committing the cell apoptosis via the intrinsic pathway.

Most knockout mouse models targeting intrinsic pathway components die in utero by mid-gestation, while the caspase 9 knockout mice die 3 days after birth (Hakem et al. 1998, Kuida et al. 1998) although their testicular phenotypes have not been studied. Expression of most of the intrinsic pathway components such as Bcl2l2, Bax mRNAs, and proteins (Yan et al. 2000, Meehan et al. 2001); APAF1 (Honarpour et al. 2000); and cytochrome $C$ (Narisawa et al. 2002) has been reported in early germ cell types (spermatogonia and spermatocytes) and in Sertoli cells throughout development. On the other hand, no intrinsic apoptotic pathway components (BCL2L2 and BAX) were expressed in spermatids or mature sperm (Beumer et al. 2000, Yan et al. 2000).

\section{The extrinsic (death receptor) pathway}

The extrinsic pathway represents another major mode of caspase-activated cell death, in which the cell surface death receptors called FAS receptors (FASRs) have emerged as the key regulators (Fig. 1). FAS is a transmembrane receptor protein, and contains a 'death domain' and initiates apoptosis following binding to its ligand (FASL) and then to FASR. This trimerization of ligand-receptor complex recruits the intracellular adaptor molecule, FAS-associated death domain, which binds several molecules of caspase 8 pro-enzyme, resulting in proteolytic activation. Then, activated initiator caspases cleave executioner caspases leading to apoptosis (Nagata \& Golstein 1995, Nagata 1997; Fig. 1).

The activation of this pathway has been shown in physiological and experimentally induce germ cell apoptosis (Shaha 2007). In rodents and man, FAS has been localized to germ cells, spermatocytes, and spermatids, while FASL to Sertoli cells (Lee et al. 1997, Sugihara et al. 1997, Pentikainen et al. 1999), while neither FAS nor FASL is expressed in spermatogonia (Francavilla et al. 2000).

\section{Other apoptotic pathways and crosstalk between pathways}

The ER pathway is associated with cell death, where caspase 12 has been considered to be the main initiator caspase. In gonadotrophin-deficient hypogonadal (hpg) mice, an up-regulation of the expression of caspase 12 mRNA level 
has been observed (Chausiaux et al. 2008), suggesting an involvement of this pathway in the testis. Crosstalk between apoptotic pathways occurs at some levels. In some occasions, caspase 8-mediated activation is less efficient, and/or activation of the effectors is inhibited by the members of the 'inhibitor of apoptosis protein' family (Scaffidi et al. 1999, Riedl \& Shi 2004). In such a case, a caspase 8-generated cleavage product of BID, a pro-apoptotic BCL2 family member, causes the release of cytochrome $C$ from the mitochondria and leads to cell death via the intrinsic apoptotic pathway (Hengartner 2000; Fig. 1). This type of crosstalk has been observed for spermatocyte apoptosis during the first wave of spermatogenesis in rats (Lizama et al. 2007). However, whether this crosstalk exists in other germ cell death models such as hormone deprivation remains unknown.

Following biochemical changes, morphological changes ensue; dying cells shrink and detach from the neighboring cells, and the nucleus becomes markedly condensed. The nucleolus and nuclear membrane of apoptotic cell then break and form discrete membrane-bound 'apoptotic bodies'. The most notable morphological feature of apoptosis is the cleavage of genomic DNA into internucleosomal fragments of about 180-200 bps (Douglas et al. 1995, Li et al. 1995), which is a hallmark of apoptosis. In addition, early modification of the apoptotic cell involves the exposure of phosphatidylserine (PS) on the outer side of the plasma membrane. The PS-exposing apoptotic cells then bind to receptors on the phagocytotic cells such as macrophages, which then engulf the cell fragments. Both in vitro and in vivo Sertoli cells recognize, engulf, and remove PS-exposing apoptotic spermatogenic cells (reviewed in Nakanishi \& Shiratsuchi (2004)).

\section{Mechanisms of germ cell proliferation}

Germ cells proliferate through a series of mitotic and meiotic divisions during which genetic stability is maintained through the precisely regulated DNA duplication, repair, and segregation mechanisms of the cell cycle, which can be divided into four discrete phases. During the cell cycle, spermatogonia grow in the $G_{1}$ phase, synthesize DNA in the $S$ phase, prepare for mitosis in the $G_{2}$ phase, and undergo mitosis and meiosis in the $\mathrm{M}$ phase (consists of four subphases: prophase, metaphase, anaphase, and telophase; Fig. 2). There are two meiotic divisions in spermatocyte development. In prophase I, metaphase I, anaphase I, and telophase I of meiosis I, spermatocytes transform to give rise to leptotene, zygotene, pachytene spermatocytes and diplotene cells respectively. In meiosis II, both diplotene cells undergo further reduction without DNA synthesis and give rise to four haploid germ cells, marking the completion of the $M$ phase (Fig. 2; reviewed in Wolgemuth et al. (2002)). At the end of the cell cycle, a cell has two potential fates; the cell can enter either a new cycle or into a quiescence phase $\left(G_{0}\right)$.



Figure 2 A schematic diagram representing the cell cycle of germ cells. The cell cycle has been divided into four discrete phases: $\mathrm{S}$ phase (DNA synthesis), $\mathrm{M}$ phase (mitosis and meiosis), and two gap regulatory phases $G_{1}$ and $G_{2}$ prior to $M$ phase and $S$ phase respectively. $M$ phase can be further divided into four subphases: prophase, metaphase, anaphase, and telophase. At the completion of cell cycle after $M$ phase, a cell has two fates: the cell can either start a new cycle or enter a quiescence phase, $\mathrm{G}_{0}$ (e.g. Sertoli cells after puberty). During M phase, spermatogonia undergo mitosis, while spermatocytes undergo two meiotic divisions. During meiosis I, at prophase I: leptotene, at metaphase I: zygotene, at anaphase I: pachytene and at telophase I: diplotene, spermatocytes are observed. During meiosis II, diplotene spermatocytes undergo further meiotic divisions to eventually give rise to haploid spermatids.

For example, Sertoli cells around puberty enter $G_{0}$ phase and remain quiescent. A cell can stay in $G_{0}$ phase for a varying amount of time before resuming proliferation. For example, undifferentiated spermatogonia become arrested in $\mathrm{G}_{1}-\mathrm{G}_{0}$ phase at stages II-III of spermatogenesis, and resume proliferation at stage IX and then undergo 9-11 mitotic divisions during spermatogonial development (de Rooij 2001). The cell cycle can be stopped at specific checkpoints $\left(G_{1}\right.$ and $\left.G_{2}\right)$, or the cells can be withdrawn from the cell cycle at any phase. Generally, cells only proliferate if they are stimulated by external factors such as mitotic factors or growth factors, in the absence of which they are directed to $G_{0}$ phase, a process that can be reversed upon 
appropriate stimulation. Failure to receive survival factors restricts the cell's ability to proceed to the next phase and triggers apoptotic pathways resulting in death (Rodriguez et al. 2006).

\section{Hormonal regulation of spermatogenesis}

Germ cell proliferation and survival depend heavily on gonadotrophin-dependent mechanisms (McLachlan et al. $2002 a$ ), the subject of this review, although some aspects appear to be gonadotrophin independent (Allan et al. 2004). FSH exerts its biological effects via G protein-coupled FSH receptors (FSHRs) found on the plasma membrane of the Sertoli cells (Simoni et al. 1997, Heckert \& Griswold 2002). FSH signaling on Sertoli cells is known to activate at least about five signaling pathways, such as cAMP and protein kinase, MAP kinase, calcium, phosphatidylinositol 3-kinase, and phospholipase $\mathrm{A}_{2}$ pathways (reviewed in Walker \& Cheng (2005)). These pathways eventually activate cAMPresponsive element (CRE)-binding protein (CREB), and then transcribe downstream target genes of spermatogenesis. Testosterone is synthesized by Leydig cells upon LH stimulation (de Kretser et al. 1971, Wahlstrom et al. 1983). Testosterone exerts its biological effects on spermatogenesis via androgen receptors (ARs) that are localized in the Sertoli cells (reviewed in Silva et al. (2002)). There is also evidence for a non-genomic action of androgens, in which testosterone elicits responses through secondary messengers such as cAMP and signaling pathways different from classical AR-mediated transcription (reviewed in Walker (2003)). Cellular responses following secondary messenger or signaling pathways in Sertoli cells include the phosphorylation of CREB and CRE modulator, and these transcription factors have also been shown to be regulated by FSH (West et al. 1994, Scobey et al. 2001). Despite common pathways being activated by FSH and testosterone, some differences exist, for example, testosterone does not up-regulate cAMP production in Sertoli cells (reviewed in Walker \& Cheng (2005)). In recent years, the characterization of the signaling pathways regulated by FSH and testosterone has been an important step toward the understanding of how these hormones support spermatogenesis. For example, observations of non-genomic effects of androgens are found to be transient and fast $(20-30 \mathrm{~s})$, while modulation of gene transcription via the ARs takes at least 30-45 min (Shang et al. 2002). Therefore, it is likely that further studies on the non-genomic signaling will identify additional hormone-regulated genes and factors that are required to support spermatogenesis.

\section{Roles of FSH in spermatogenesis}

The size of the Sertoli cell population is set in early postnatal life, and it is a major determinant of sperm output in the adult animal. As spermatogenesis is initiated, Sertoli cells undergo a period of proliferation in rodents, and numerous in vivo and in vitro studies have shown FSH to be a key regulator (Sharpe et al. 2003). The general view of Sertoli cells in adulthood is that the population is fixed and unmodified by hormonal manipulation after puberty (Sharpe et al. 2003). Yet, new evidence derived from gonadotrophin-deficient hamsters and men shows that Sertoli cells retain proliferative ability and can re-acquire features reminiscent of immature Sertoli cells (Meachem et al. 2005a, 2007, Tarulli et al. 2006). The short-term manipulation of FSH levels in rats and data from transgenic mice models have identified various sites of FSH action in the first wave of spermatogenesis and in adulthood (reviewed in McLachlan et al. (2002a)), including the recent findings of roles in spermatogonial survival and adhesion complexes in spermiation (Beardsley \& O'Donnell 2003, Ruwanpura et al. 2008a,b). On the other hand, the individual role of FSH action in human spermatogenesis is largely undefined. These issues are difficult to address in men for many reasons, including ethical, practical, and physiological considerations. Despite these difficulties, the quality data emerging on gonadotrophin regulation of human spermatogenesis suggest that FSH and/or LH have impact on spermatogonia, meiosis, and spermiation (Zhengwei et al. 1998a,b, McLachlan et al. 2002c, Matthiesson et al. 2005, 2006).

\section{Short-term studies}

We have divided the effects of FSH into short and long term purposely. Numerous short-term studies on mammals have reported the effects of FSH manipulation on spermatogenesis (reviewed in McLachlan et al. (2002a)). Although data provide important information, the data are incomplete due to the complex and dynamic nature of spermatogenesis. However, maintenance and restoration of full spermatogenesis (thus long-term effects), in cases where there are no testosterone actions, have not been possible until now due to the unavailability of homologous FSH preparations and/or efficient models to fully withdraw hormones. Important lessons can be learnt from both short- and long-term studies. The role of FSH is better defined for adult spermatogenesis than in the first wave; however, it is generally considered that, subtle or otherwise, differences are apparent. For gonocytes, we have documented that FSH plays no role in their maturation into type A spermatogonia in vivo, as no changes in apoptotic and proliferation rates have been observed after acute FSH suppression (Meachem et al. 2005b). In agreement, gonocyte survival is not affected by FSH treatment in organ cultures of fetal and neonatal rat testes (Boulogne et al. 1999). However, FSH combined with other factors such as follistatin, activin, or c-kit has promoted gonocyte maturation (Meehan et al. 2000) and survival (reviewed in Orth et al. (2000)). Additionally, gonocyte migration appears to be dependent in part on the interaction of c-kit and its FSH-regulated ligand, stem cell factor (reviewed in 
Orth et al. (2000)). Therefore, it is likely that FSH influences a set of interacting factors to regulate gonocyte development.

Spermatogonia FSH plays a major role in the regulation of spermatogonial population in rodents (reviewed in McLachlan et al. (2002a)). During the $15 \mathrm{dpp}$ of first wave of spermatogenesis, FSH acts as a survival factor rather than as a proliferative factor (Meachem et al. 2005b). This contrasts with in vitro data suggesting that FSH is essential for the proliferation of undifferentiated type A spermatogonia in immature testis culture, whereas FSH combined with activin (which inhibits FSH secretion) markedly depressed their proliferation (Boitani et al. 1993, 1995). Therefore, there are differences that exist between the subpopulations of spermatogonia as to whether FSH acts as a mitogenic factor, and this needs to be addressed. In adult rats, short-term manipulation of FSH levels has resulted in a time-dependent change in type A/intermediate spermatogonial number (reviewed in McLachlan et al. (2002a)), with the most sensitive types being the $\mathrm{A}_{3}-\mathrm{A}_{4}$ spermatogonia in stages XIV-I (Meachem et al. 1999), which are the stages corresponding to maximal FSHR number (Kangasniemi et al. 1990), mRNA expression (Heckert \& Griswold 1991), and the highest cAMP production (Parvinen et al. 1980). FSH acts as a survival factor for spermatogonia (Krishnamurthy et al. 2000), and we have shown it to act in a stage-specific manner on stages XIV-III and VI-VIII tubules (Ruwanpura et al. 2008a). While others have reported that FSH stimulates DNA synthesis in spermatogonia and preleptotene spermatocytes at stages I and VIII-IX in vitro of adult rat seminiferous tubule segments (Henriksen et al. 1996). Inconsistencies with regard to FSH acting as a mitogenic factor may arise from the use of different experimental models. The reason for FSH having little to no effect on proliferation in vivo may be the potentially low concentration of biologically active FSH is present and thereby providing support sufficient for proliferation.

Our laboratory demonstrated that acute FSH suppression induces spermatogonial apoptosis via the intrinsic apoptotic pathway, and not via the extrinsic apoptotic pathway in immature and adult rats, as evidenced by increased activated caspase 9-positive spermatogonia, but not by activated caspase 8-positive spermatogonia (Ruwanpura et al. 2008a,b). This may occur due to developmentally controlled changes in the expression of intrinsic pathway regulators such as BCL2 family proteins during the first wave of spermatogenesis. Antiapoptotic genes such as $B c l 2 l 2, B c l 2$, and $B a x$ are expressed in juvenile spermatogonia, but only $B c l 2 l 2$ is detected in spermatogonia of adult mice. Bcl2l2 mRNA was shown to be up-regulated by FSH in vitro, and the Bcl2l2 knockout mice had elevated spermatogonial apoptosis indicating the potential influence of BCL2 family members on cellular responses (Meehan et al. 2001). Additional evidence for the intrinsic pathway regulation of spermatogonial survival was provided by the Bax gene knockout mice, wherein spermatogonia accumulate suggesting failed physiological apoptosis (Knudson et al. 1995, Russell et al. 2002), and when Apaf1 was removed via gene-targeted deletion, high numbers of degenerating spermatogonia were observed. (Honarpour et al. 2000). Collectively, these data reveal that FSH regulates spermatogonial apoptosis via the intrinsic pathway in rodents.

In humans, spermatogonia are highly sensitive to gonadotrophins as evidenced by decreases in type B ( $\sim 10-20 \%$ of control) and type A pale (40\% of controls) spermatogonia following 12 weeks of gonadotrophin suppression (Zhengwei et al. 1998a, McLachlan et al. 2002c). These observations held true in later androgen-based contraceptive studies involving the addition of a gonadotrophin-releasing hormone antagonist or a $5-\alpha$ reductase inhibitor to further withdraw gonadotrophic/androgenic support for spermatogenesis (Matthiesson et al. 2005). However, differences were noted between primates and humans in terms of sensitivities of spermatogonial subtypes to FSH and/or androgens. Several studies using monkeys have indicated that type A spermatogonia, followed by type B spermatogonia, are reduced following gonadotrophin suppression (reviewed in Meachem et al. (2001)) as a result of altered proliferation of type A pale spermatogonia (Simorangkir et al. 2005), and also, it must be noted that the species of monkeys used can yield differences in outcomes and thus conclusions drawn (Marshall et al. 2005). The specific effect of FSH and $\mathrm{LH}$ on spermatogonial development in humans is poorly understood. However, data from our laboratory show that FSH appears to maintain spermatogonia up to pachytene spermatocytes (Matthiesson et al. 2006), suggesting that FSH plays an important role that is similar to that shown in the rats. The data provided the new finding that gonadotrophins in men act as survival factors for spermatogonia by regulating the intrinsic apoptotic pathway, not the extrinsic apoptotic pathway, while playing no role in proliferation (Ruwanpura et al. 2008c). In gonadotrophinsuppressed men, it has not been possible to distinguish whether survival of type A and/or B spermatogonial subpopulations is affected, but since type A spermatogonial numbers are unchanged in these men after 6 weeks of gonadotrophin suppression (McLachlan et al. 2002c), it is speculated that B spermatogonia undergo apoptosis.

Spermatocytes/spermatids FSH plays some role in meiosis and spermiogenesis in adulthood, although our understanding of the first wave is rudimentary. Some studies have suggested that FSH is important for the progression of meiosis in the first wave of rat spermatogenesis (Vihko et al. 1991), but this has not been studied in the last decade. In adults, FSH appears to support meiosis as shown by a maintenance of preleptotene spermatocytes and partial maintenance of pachytene spermatocytes following the administration of GNRH antagonist with FSH (Chandolia et al. 1991, Sinha-Hikim \& Swerdloff 1995). Whether these are direct effects remains uncertain as FSH may act indirectly by the regulation of AR number (and its associated pathways, Verhoeven \& Cailleau 1988) or that of androgen-binding protein (Louis \& Fritz 1979). 
However, acute FSH suppression has led to a reduction in pachytene spermatocyte numbers at stage VII in the presence of normal levels of androgens (Meachem et al. 1999), suggesting a direct effect of FSH. FSH plays a role in spermiogenesis (McLachlan et al. 1995, Meachem et al. 1998) perhaps by regulating adhesion and junctions between Sertoli cells and spermatids (Muffly et al. 1994, Sluka et al. 2006). Our laboratory has identified that sperm fail to be released after passive FSH immunization (Saito et al. 2000), indicating a role of FSH in spermiation process.

FSH (in the presence of normal levels of androgens) supports spermatocyte survival by regulating both the intrinsic and extrinsic apoptotic pathways during the onset of meiosis (Ruwanpura et al. 2008b). In adult rodents, FSH, together with testosterone, supports the survival of meiotic cells and spermatids via both the intrinsic and extrinsic pathways (Pareek et al. 2007, Chausiaux et al. 2008, Ruwanpura et al. 2008a). Increases in FAS and BAX protein and their mRNA levels (Pareek et al. 2007), increases in activated caspase 9- and caspase 8-positive spermatocytes (Ruwanpura et al. 2008a) after GNRH antagonist treatment, and increases in the expression of Casp 8 and Casp 9 mRNAs in hpg mice (Chausiaux et al. 2008) suggest a synergistic action of FSH and testosterone in regulating both the intrinsic and extrinsic pathways. However, in adult rats, acute FSH suppression (in the presence of normal levels of androgens) alone had little or no effect on caspase activity of meiotic and spermatogenic cells (Ruwanpura et al. 2008a), suggesting that testosterone promotes later germ cell survival in rats. The data regarding whether FSH acts as a mitogenic factor for spermatocytes are conflicting. Adult rodent data of ours and others provide no evidence that FSH modulates their proliferation (McLachlan et al. 1995, Krishnamurthy et al. 2000, Ruwanpura et al. 2008a).

In humans, it is not clear whether FSH plays a direct role in meiosis and spermiation. However, a study investigating the relative role of FSH and $\mathrm{LH}$ in the maintenance of human spermatogenesis shows some indications that FSH appears to be more effective than $\mathrm{LH}$ (or intratesticular androgens) in supporting pachytene spermatocytes when simultaneously administered with LH (Matthiesson et al. 2006). Similar to rodents, FSH, together with testosterone, acts as a survival factor for spermatocytes and spermatids by regulating both the intrinsic and the extrinsic apoptotic pathways in men. Human seminiferous tubules cultured in a medium without FSH or testosterone showed significantly increased DNA fragmentation in primary spermatocytes and elongating/ elongated spermatids via the intrinsic and extrinsic apoptotic pathways (Tesarik et al. 1998, 2002, Pentikainen et al. 1999, Vera et al. 2006).

\section{Long-term studies}

Earlier studies claimed that testosterone alone is capable of restoring spermatogenesis qualitatively in adults (Buhl et al. 1982, Awoniyi et al. 1992) without stimulating pituitary FSH
(McLachlan et al. 1994). Data from our laboratory demonstrated that FSH does not have the ability to rescue full spermatogenesis following chronic FSH and androgen action depletion in rats; however, mild increases in spermatogonia and flow on the effect of other germ cells up to pachytene spermatocytes have been observed (SM Ruwanpura, PG Stanton, DM Robertson, RI McLachlan, Y Makanji and SJ Meachem, unpublished observations). Short-term studies clearly show that upon FSH stimulation, spermatogonia are restored in the presence of either low or normal levels of androgens (McLachlan et al. 1995, Meachem et al. 1998), leading to the assumption that even a low level of androgen action is essential for potentiating the FSH response. Similarly, transgenic mice models show that FSH supports early germ cell development, but that it is incapable of supporting full spermatogenesis (Allan et al. 2004, Chang et al. 2004, De Gendt et al. 2004). The testis of the hpg mice lacking both FSH and LH showed that testosterone alone can qualitatively complete the first wave of spermatogenesis (Singh et al. 1995), although effects on gonocyte numbers are not apparent (Baker \& O'Shaughnessy 2001). Accordingly, the AR Sertoli cell knockout mice show arrest at the late spermatocyte (Chang et al. 2004, De Gendt et al. 2004), and suggest that FSH alone can support mitosis and meiosis during the first wave, but that androgen action is absolutely necessary for the completion of meiosis and spermiogenesis. tgFSH/hpg mice and $h p g$ mice after FSH administration (Singh \& Handelsman 1996, Allan et al. 2004) show increases in early germ cell number up to early spermatids but the absence of spermatozoa. Although mice deficient in FSH protein or receptor show that FSH is not needed for fertility, these mice have reduced levels of sperm (Dierich et al. 1998, Krishnamurthy et al. 2000, reviewed in Sairam \& Krishnamurthy (2001) and Wreford et al. (2001)). Transgenic models of FSHRKO, FSH $\beta \mathrm{KO}$, and tgFSH/hpg mice have shown changes in Sertoli cell number (reviewed in Sairam \& Krishnamurthy (2001) and Allan et al. (2004)), and thus effects on early germ cell populations may be a direct effect of perturbed Sertoli cell proliferation during the first wave of spermatogenesis. Additionally, it has been suggested that the transition of round spermatids into elongated spermatids is a target of direct FSH action as identified in the FSHRKO and FSH $\beta K O$ transgenic models (reviewed in Sairam \& Krishnamurthy (2001)). In these transgenic models, it has been demonstrated that FSH supports both survival and proliferation of germ cells. Adult tgFSH/hpg mice provide compelling evidence that FSH supports spermatogonial proliferation and the stimulation of meiotic and post-meiotic germ cell development (Haywood et al. 2003). In immature hpg mice testes, an up-regulation of the intrinsic pathway transcripts caspase 9 and Apaf1 was documented in spermatogonia, as assessed by microarray analysis, indicating the involvement of intrinsic apoptotic pathway in the spermatogonial death in response to deficiency in gonadotrophins (Chausiaux et al. 2008) although it is anticipated to be a FSH-specific effect. 


\section{Role of testosterone in spermatogenesis}

It is beyond question that testosterone is needed for adult spermatogenesis. The main targets of testosterone action are meiosis and spermiogenesis with ample data being provided in rodents. In immature testes, testosterone is essential for gonadal formation and testicular differentiation. Over the last 5 years, evidence is mounting that testosterone is involved in Sertoli cell differentiation in early postnatal life (Buzzard et al. 2003, Haywood et al. 2003, reviewed in Sharpe et al. (2003) and Walker (2003)). It has been reported that testosterone in conjunction with thyroid hormone and retinoic acid may be involved in suppressing Sertoli cell proliferation in vitro (Buzzard et al. 2003), leading to the cessation of proliferation of Sertoli cells (reviewed in Walker (2003)), and that testosterone may act as a suppressor of Sertoli cell development. Although data seem to be model dependent in that Sertoli cell numbers remain unchanged in mice lacking Sertoli cell androgen (De Gendt et al. 2004) and LH receptors (Allan et al. 2004), Sertoli cell numbers remained unchanged. In contrast, the phenotype of hypogonadic rat appears to be a result of Leydig cell dysfunction, displaying low levels of testosterone with high levels of gonadotrophins (Yagi et al. 2007), and suggests that the lack of testosterone in this model leads to Sertoli cell apoptosis in early development. Despite the role testosterone plays in Sertoli cells, the importance of testosterone in the first wave of spermatogenesis requires further investigation.

\section{Germ cells}

Gonocytes The role of testosterone in germ cell development during the first wave of spermatogenesis is ill-defined. One study has documented that the lack of testosterone can contribute to the occurrence of multinucleated gonocyte proliferation (Scott et al. 2007) during the early stage of the first wave of rat spermatogenesis. However, AR knockout mice with testicular feminization did not demonstrate any occurrence of multinucleated proliferating gonocytes, suggesting an androgen-independent effect (Ferrara et al. 2006); however, this may be due to differences between species.

Spermatogonia There is no evidence to suggest that testosterone is required for spermatogonial development in the first wave of spermatogenesis and adult rats. In addition, transgenic mice models reported that testosterone plays no role in spermatogonial development (Haywood et al. 2003, reviewed in Holdcraft \& Braun (2004)). What is clear is that supraphysiological levels of serum (Meachem et al. 1998, Shetty et al. 2001) and testicular testosterone are detrimental to spermatogonial development. This is shown elegantly in irradiated/chemotherapy-treated rats and in the juvenile spermatogonial mutant mice, where suppression of supraphysiological testicular testosterone (fourfold normal) is required for the induction of spermatogonial development
(Shetty et al. 2001). Similar to rodents, it is presumed that the reduction in spermatogonial numbers in men following gonadotrophin suppression may be purely due to the reduced levels of FSH rather than to those of testosterone.

Spermatocytes/spermatids Testosterone action is critical for the completion of meiosis, entry into and progress through, and spermiogenesis in rodents (reviewed in McLachlan et al. (2002a) and Haywood et al. (2003)). In immature rats, testosterone is an absolute requirement for the completion of the first wave of spermatogenesis during puberty (Cameron et al. 1993, Marathe et al. 1995). Similarly, AR Sertoli cell knockout mice have also displayed arrest at late spermatocytes and beyond (Chang et al. 2004, De Gendt et al. 2004), suggesting that the completion of meiosis and spermiogenesis is dependent on androgen action in the first wave. In adults rats, gonadotrophin suppression induced by testosterone implants had a modest impact on the initiation of meiosis by suppressing early spermatocyte number and pachytene spermatocytes at stages I-VII with reduced number of spermatids (Meachem et al. 1997, 1998), and this is further reduced upon the elimination of residual testosterone in these models with an anti-androgen (Meachem et al. 1997, El Shennawy et al. 1998, O’Donnell et al. 1999). Similarly, in adult $h p g$ mice, testosterone alone facilitated the completion of meiosis, as evidenced by the production of round spermatids from pachytene spermatocytes (Haywood et al. 2003). Several studies from our laboratory have pinpointed particular sites in rat spermiogenesis at which testosterone action is required. Testosterone is important for the conversion of step 7 round spermatids into step 8 spermatids by regulating the adhesion between Sertoli round/elongating/elongated spermatids at the apical ectoplasmic specialization (ES) adherens junctions (O’Donnell et al. 1996, 2006, Wong et al. 2005). However, testosterone suppression had no effect on the structure of the ES complexes (O'Donnell et al. 2006). It has been shown that testosterone regulates ES-restricting proteins such as $\beta 1$-integrin, Tyr-phosphorylated focal adhesion kinase (p-FAK), and c-SRC. Therefore, it is believed that testosterone regulates the $\mathrm{p}-\mathrm{FAK}-\mathrm{c}-\mathrm{SRC}$ protein complex via the ERK signaling pathway (Wong et al. 2005, Cheng \& Mruk 2009). In addition, testosterone together with FSH has been found to support spermiation (Saito et al. 2000).

The precise mechanism by which testosterone regulates spermiogenesis is not defined; however, stimulation of adhesion molecules and/or regulation of cell survival are highly likely. The role that testosterone plays in germ cell survival during the first wave of spermatogenesis has not been explored in the last decade; however, studies have shown that testosterone regulates spermatocyte and spermatid survival in in vivo and in vitro conditions of immature rats (Tapanainen et al. 1993, Marathe et al. 1995). A recent study has reported the regulation of both the intrinsic and extrinsic pathway components, Bcl212, Casp 8 , and Casp 9 , in $h p g$ mice at 13 dpp; 
however, the specific contribution of testosterone to this process is not known (Chausiaux et al. 2008). In adults, several studies have shown that testosterone withdrawal from rat testis leads to an increase in meiotic and spermatogenic cell apoptosis in a stage-dependent manner, and suggested that testosterone may act as a survival factor (Billig et al. 1995, Henriksén et al. 1995, Marathe et al. 1995, Bakalska et al. 2004). Few studies have investigated the molecular mechanism by which testosterone affects germ cell apoptosis in rodents. It has been suggested that acute testosterone withdrawal by EDS treatment leads to an increased spermatocyte and spermatid apoptosis with a significant increase in FAS content (Nandi et al. 1999). Nonetheless, the co-localization of FASL and FASR correlated with spermatocyte and spermatid death after testosterone withdrawal (Woolveridge et al. 1999). Collectively, these suggest the involvement of the extrinsic apoptotic pathway. In addition, a significant increase in BAX was observed after EDS-induced androgen withdrawal in rat testis (Woolveridge et al. 1999). It has also been shown that BCL2L2 may be important as Bcl2l2-deficient mice are sterile due to the loss of spermatocyte and spermatid apoptosis (Ross et al. 1998). Since BAX and BCL2L2 act together as a dimer via the intrinsic pathway during apoptosis, it can be postulated that testosterone withdrawal induces spermatocyte and spermatid apoptosis via the intrinsic pathway. However, whether the intrinsic pathway is regulated by testosterone in rodents requires further investigation.

In humans, using available clinical models of chronic gonadotrophin suppression, it has been deduced that testosterone is important for the conversion of round spermatids (Matthiesson et al. 2006). Unlike rat models, detachment of round spermatids from Sertoli cells has not been observed in gonadotrophin-suppressed men (Zhengwei et al. 1998b, McLachlan et al. 2002c), despite appropriate time periods being studied. Despite the presence of normal numbers of elongated spermatids prior to spermiation in testis biopsies taken from men after 6 weeks of combined testosterone and progestin treatment, most men are oligospermic throughout the treatment phase, suggesting that spermiation failure underlies the initial suppression of sperm counts (McLachlan et al. 2002c, Matthiesson et al. 2005, 2006). Conversely, concomitant administration of human chorionic gonadotropin (hCG) with male hormonal contraception demonstrated normal spermiation (Matthiesson et al. 2006), suggesting the importance of testosterone for spermiation. In humans, testosterone alone or together with FSH acts as a survival factor for spermatocytes and spermatids by regulating both the intrinsic and the extrinsic apoptotic pathways (Tesarik et al. 1998, 2002, Pentikainen et al. 1999, Vera et al. 2006). This was also observed in the non-human primate model, where increases in spermatocyte and spermatid apoptosis were observed in rhesus monkeys following gonadotrophin suppression (Zhou et al. 2001, Zhang et al. 2003). It has also been suggested that administration of exogenous testosterone to rhesus monkeys induced spermatocyte and spermatid apoptosis by increasing FAS/FASL (Zhou et al. 2001) and BCL2/BAX (Zhang et al. 2003) expression, indicating the activation of both the extrinsic and intrinsic apoptotic pathways respectively.

\section{FSH and testosterone co-operativity}

Even though FSH and testosterone have independent roles in spermatogenesis, they also act in a co-operative manner to promote quantitative spermatogenesis presumably by modulation of post-receptor events within Sertoli cells. Both FSH and testosterone act in a stage-dependent manner and act at different cellular sites during spermatogenesis in order to optimize the spermatogenic process. Synergy between FSH and testosterone is observed at spermatocyte development, wherein only partial maintenance or restoration of meiosis is achieved by individual hormone suppression or replacement, while combined exposure is much more effective (reviewed in McLachlan et al. (2002a)). There are few studies to suggest that testosterone together with FSH promotes spermiogenesis by promoting adhesion of round spermatids to Sertoli cells (O'Donnell et al. 2006, Sluka et al. 2006). FSH and testosterone synergy is mainly demonstrated in spermiation. The suppression of both hormones led to further induction of spermiation failure to about $90 \%$ compared with their individual effects, which were about 15\% (Saito et al. 2000), and this process is likely mediated by $\beta 1$-integrin in an ILK-independent mechanism (Beardsley \& O'Donnell 2003).

It has been suggested that both FSH and testosterone act as survival factors of germ cells in immature and adult rats by regulating both the intrinsic and extrinsic apoptotic pathways (Russell et al. 1993, Tapanainen et al. 1993, Sinha-Hikim \& Swerdloff 1995, Meachem et al. 2005b, Ruwanpura et al. 2008a). The molecular mechanisms of FSH and testosterone synergy remain largely undefined, but there is a possibility that FSH may affect AR action by regulating AR number and androgen-binding proteins (Ottenweller et al. 2000). It is not known whether FSH and testosterone co-operativity is required for the proliferation of germ cells; however, there is a possibility that only a small amount of either hormone may be required to promote proliferation.

Observed differences in the ability of FSH and testosterone to either maintain or restore spermatogenesis may be explained in part by differences in experimental models/ designs, rather than by their intrinsic activities. There are many reports that a lower dose of either hormone is equally effective in promoting spermatogenesis when in the presence of other hormones (Meachem et al. 1998, SM Ruwanpura, PG Stanton, DM Robertson, RI McLachlan, Y Makanji and SJ Meachem, unpublished observations). 


\section{Summary}

Even though hormones act on all phases of spermatogenesis in rodents, there are only three phases of spermatogenesis that are regulated by gonadotrophins in men: i) the maturation of type A spermatogonia to type B spermatogonia, ii) meiosis, and iii) spermiation, both acutely and chronically (Fig. 3). FSH acts on the development of spermatogonia by controlling their survival mechanisms in rodents; however, the individual effect of FSH and $\mathrm{LH}$ on human spermatogenesis is ill-defined, and based on rodent data, one could speculate that FSH plays an important role to support spermatogonia. $\mathrm{FSH}$ and testosterone action is important for the progression of meiosis, perhaps by the regulation of the survival via the intrinsic and the extrinsic apoptotic machineries, and also spermiation in both rodents and humans. However, there are differences between rodent data and human data as to whether hormones play any role during spermiogenesis by involving adhesion complex proteins in humans. Male germ cells need hormones to survive by controlling the intrinsic and extrinsic apoptotic pathways. 'Do germ cells proliferate independent of hormones, but rather via genetic control' is one of the main questions needed to be answered to understand the hormonal and genetic control of spermatogenesis. It is important to investigate whether human data are similar to rodent data, and this will allow us to investigate the effect of specific hormones in germ cells and molecular pathways which underpin these regulations (Fig. 4).

\section{Sites \& effects}

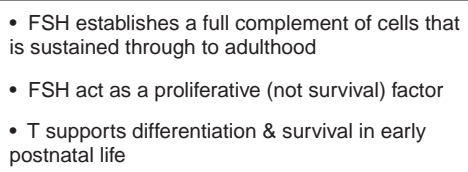

- FSH establishes a full complement of cells that is sustained through to adulthood

- FSH act as a proliferative (not survival) factor

- T supports differentiation \& survival in early postnatal life

\section{Gaps in knowledge}
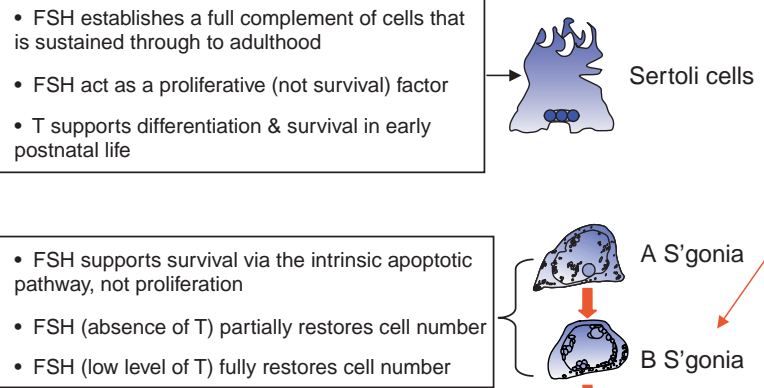

- FSH supports survival via the intrinsic apoptotic pathway, not proliferation

- FSH (absence of T) partially restores cell number

- FSH (low level of T) fully restores cell number

- FSH \& T support entry into meiosis and survival via the intrinsic \& the extrinsic apoptotic pathways, not proliferation

- FSH \& T promote survival via the intrinsic \& extrinsic apoptotic pathways, not proliferation

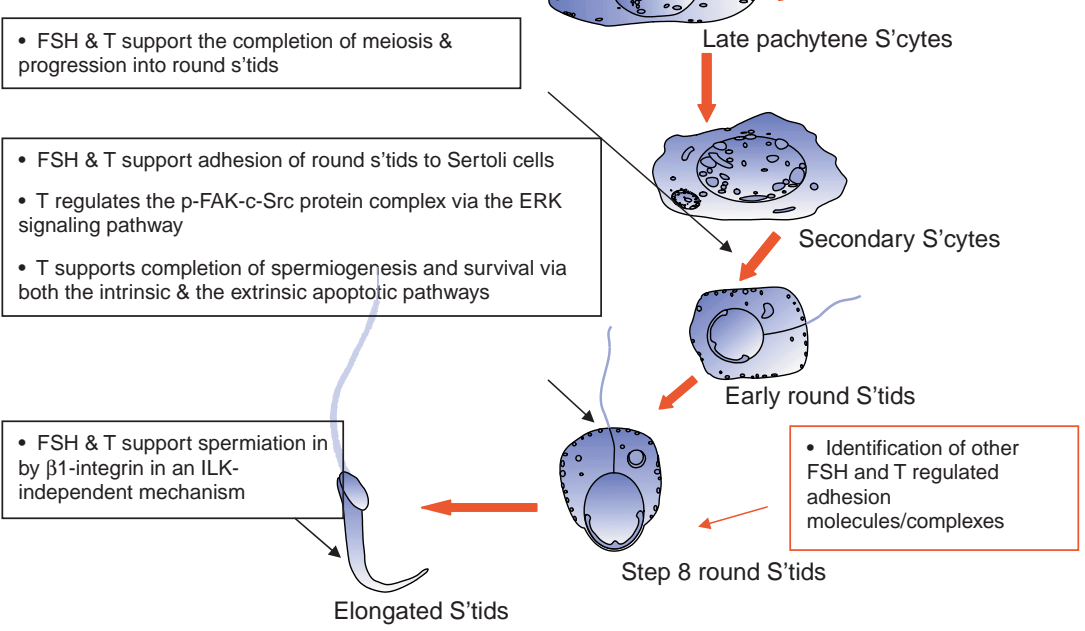

Figure 3 A diagram summarizing the sites, cellular mechanisms, and molecular pathways underpinning FSH and testosterone ( $\mathrm{T}$ ) actions on immature and adult rodent spermatogenesis based on the findings from the literature (in black) and unsolved issues (in red). 


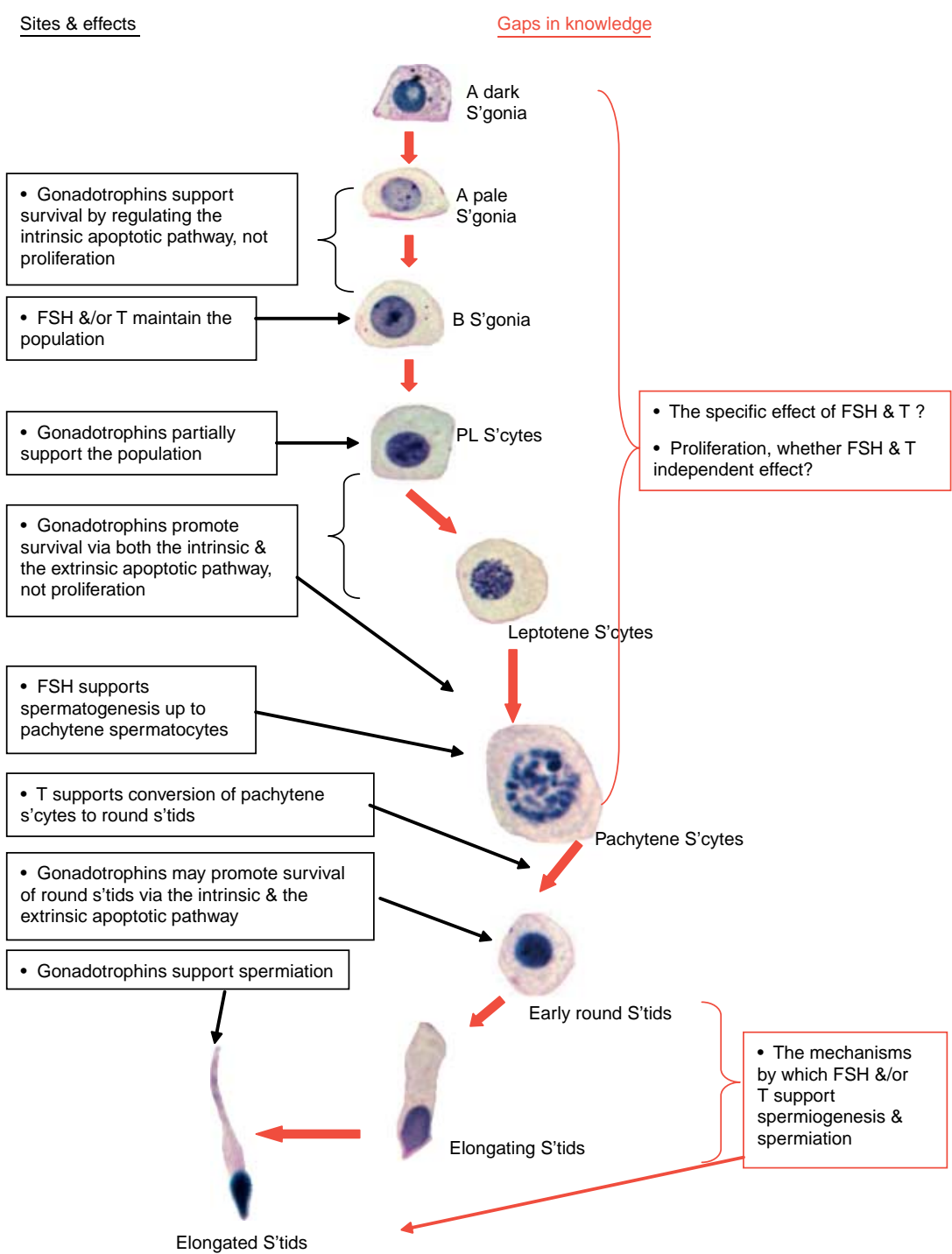

Figure 4 A diagram summarizing the sites, cellular mechanisms, and molecular pathways underpinning gonadotrophin (FSH and testosterone (T)) actions on human spermatogenesis based on the findings from the literature (in black) and unsolved issues (in red).

\section{Conclusions}

Since the turn of the millennium, there has been a considerable improvement in our understanding of the regulation of germ cell progression. Mouse models, better and wider application of morphometric analysis, evolution of technology such as microscopy and more sensitive hormone assay, new and better molecular probes, and of course the genomic revolution have all underpinned this progress. In terms of the hormonal control of specific spermatogenic sites, most controversies have been remedied, with attention being turned to understand mechanistic actions that each hormone procures. Even though there are appreciable species differences, there are also likenesses with data demonstrating that different sites of spermatogenesis either rely on hormones almost exclusively or co-jointly. For example, data show that FSH predominantly regulates spermatogonial development, while testosterone regulates the latter phase of spermiogenesis, while both FSH and testosterone seem to be equally important in supporting spermatocyte development.

Now more than ever, the molecular pathways that underpin the hormonal response are being identified, and although we are only at the tip of the iceberg, it is unequivocal that the proteomic revolution will play a major hand in unraveling the precise signaling mechanisms essential for proper germ cell development, arguably more than the insurgence of sophisticated genetic technology. Post-receptor events still 
need identification, but research on how non-genomic events play a role in germ cell progression is emerging, and this area of research will undoubtedly be important for putting all the pieces of the puzzle together in an already complex mix of intercellular and intracellular interactions. Limitations still exist in understanding the specific effects of some hormones, particularly FSH, with the foremost reason being the lack of available modulating agents, a problem not encountered for androgens/steroids, although our deeper understanding is attributed to models using genetically modified mice and immunoneutralization of endogenous FSH.

In order to impact clinical management of infertility and diseases such as testicular cancer, understanding the origins of disease is vital. Understanding the precise control process of spermiation and spermatogonial development by hormones is required to achieve a better efficacy and wider and more profound spermatogenetic suppression, and therefore to the development of the world's first available male hormonal contraceptive.

\section{Declaration of interest}

The authors declare that there is no conflict of interest that could be perceived as prejudicing the impartiality of the research reported.

\section{Funding}

The work was supported by the National Health and Medical Research Council of Australia, Program Grant 14 (\# 241000- SMR, RIM, SJM).

\section{References}

Adams JM \& Cory S 1998 The Bcl-2 protein family: arbiters of cell survival. Science 281 1322-1326.

Allan CM, Garcia A, Spaliviero J, Zhang FP, Jimenez M, Huhtaniemi I \& Handelsman DJ 2004 Complete Sertoli cell proliferation induced by follicle-stimulating hormone (FSH) independently of luteinising hormone activity: evidence from genetic models of isolated FSH action. Endocrinology 145 1587-1593.

Ashkenazi A \& Dixit VM 1998 Death receptors: signalling and modulation. Science 281 1305-1308.

Awoniyi CA, Zirkin BR, Chandrashekar V \& Schlaff WD 1992 Exogenously administered testosterone maintains spermatogenesis quantitatively in adult rats actively immunized against-releasing hormone. Endocrinology $\mathbf{1 3 0}$ 3283-3288.

Bakalska M, Atanassova N, Koeva Y, Nikolov B \& Davidoff M 2004 Induction of male germ cell apoptosis by testosterone withdrawal after ethane dimethanesulfonate treatment in adult rats. Endocrine Regulations $\mathbf{3 8}$ 103-110.

Baker PJ \& O'Shaughnessy PJ 2001 Role of $s$ in regulating numbers of Leydig and Sertoli cells during fetal and postnatal development in mice. Reproduction 122 227-234.

Beardsley A \& O'Donnell L 2003 Characterization of normal spermiation and spermiation failure induced by hormone suppression in adult rats. Biology of Reproduction 68 1299-1307.

Beumer TL, Roepers-Gajadien HL, Gademan IS, Lock TM, Kal HB \& De Rooij DG 2000 Apoptosis regulation in the testis: involvement of Bcl-2 family members. Molecular Reproduction and Development $\mathbf{5 6}$ $353-359$
Billig H, Furuta I, Rivier C, Tapanainen J, Parvinen M \& Hsueh AJ 1995 Apoptosis in testis germ cells: developmental changes in gonadotrophin dependence and localization to selective tubule stages. Endocrinology 136 $5-12$.

Boitani C, Politi MG \& Menna T 1993 Spermatogonial cell proliferation in organ culture of immature rat testis. Biology of Reproduction 48 761-767.

Boitani C, Stefanini M, Fragale A \& Morena AR 1995 Activin stimulates Sertoli cell proliferation in a defined period of rat testis development. Endocrinology 136 5438-5444.

Boulogne B, Olaso R, Levacher C, Durand P \& Habert R 1999 Apoptosis and mitosis in gonocytes of the rat testis during foetal and neonatal development. International Journal of Andrology 22 356-365.

Buhl AE, Cornette JC, Kirton KT \& Yuan YD 1982 Hypophysectomized male rats treated with polydimethylsiloxane capsules containing testosterone: effects on spermatogenesis, fertility, and reproductive tract concentrations of androgens. Biology of Reproduction 27 183-188.

Buzzard JJ, Wreford NG \& Morrison JR 2003 Thyroid hormone, retinoic acid, and testosterone suppress proliferation and induce markers of differentiation in cultured rat Sertoli cells. Endocrinology 144 3722-3731.

Cameron DF, Muffly KE \& Nazian SJ 1993 Reduced testosterone during puberty results in a midspermiogenic lesion. Proceedings of the Society for Experimental Biology and Medicine 202 457-464.

Chandolia RK, Weinbauer GF, Fingscheidt U, Bartlett JM \& Nieschlag E 1991 Effects of flutamide on testicular involution induced by an antagonist of gonadotrophin-releasing hormone and on stimulation of spermatogenesis by follicle-stimulating hormone in rats. Journal of Reproduction and Fertility 93 313-323.

Chang C, Chen YT, Yeh SD, Xu Q, Wang RS, Guillou F, Lardy H \& Yeh S 2004 Infertility with defective spermatogenesis and hypotestosteronemia in male mice lacking the androgen receptor in Sertoli cells. PNAS 101 6876-6881.

Chausiaux OE, Abel MH, Baxter FO, Khaled WT, Ellis PJ, Charlton HM \& Affara NA 2008 Hypogonadal mouse, a model to study the effects of the endogenous lack of gonadotrophins on apoptosis. Biology of Reproduction 78 77-90.

Cheng CY \& Mruk DD 2009 An intracellular trafficking pathway in the seminiferous epithelium regulating spermatogenesis: a biochemical and molecular perspective. Critical Reviews in Biochemistry and Molecular Biology 5 245-263.

De Gendt K, Swinnen JV, Saunders PT, Schoonjans L, Dewerchin M, Devos A, Tan K, Atanassova N, Claessens F, Lecureuil C et al. 2004 A Sertoli cell-selective knockout of the androgen receptor causes spermatogenic arrest in meiosis. PNAS 101 1327-1332.

Dierich A, Sairam MR, Monaco L, Fimia GM, Gansmuller A, LeMeur M \& Sassone-Corsi P 1998 Impairing follicle-stimulating hormone (FSH) signalling in vivo: targeted disruption of the FSH receptor leads to aberrant gametogenesis and hormonal imbalance. PNAS 95 13612-13617.

Douglas RS, Tarshis AD, Pletcher CH Jr, Nowell PC \& Moore JS 1995 A simplified method for the coordinate examination of apoptosis and surface phenotype of murine lymphocytes. Journal of Immunological Methods 188 219-228.

El Shennawy A, Gates RJ \& Russell LD 1998 Hormonal regulation of spermatogenesis in the hypophysectomized rat: cell viability after hormonal replacement in adults after intermediate periods of hypophysectomy. Journal of Andrology 19 320-334 discussion 341-322.

Erkkila K, Pentikainen V, Wikstrom M, Parvinen M \& Dunkel L 1999 Partial oxygen pressure and mitochondrial permeability transition affect germ cell apoptosis in the human testis. Journal of Clinical Endocrinology and Metabolism 84 4253-4259.

Ferrara D, Hallmark N, Scott H, Brown R, McKinnell C, Mahood IK \& Sharpe RM 2006 Acute and long-term effects of in utero exposure of rats to di(n-butyl) phthalate on testicular germ cell development and proliferation. Endocrinology 147 5352-5362.

Franca LR, Ogawa T, Avarbock MR, Brinster RL \& Russell LD 1998 Germ cell genotype controls cell cycle during spermatogenesis in the rat. Biology of Reproduction 59 1371-1377.

Francavilla S, D’Abrizio P, Rucci N, Silvano G, Properzi G, Straface E, Cordeschi G, Necozione S, Gnessi L, Arizzi M et al. 2000 Fas and Fas 
ligand expression in fetal and adult human testis with normal or deranged spermatogenesis. Journal of Clinical Endocrinology and Metabolism $\mathbf{8}$ 2692-2700.

Green DR 2000 Apoptotic pathways: paper wraps stone blunts scissors. Cell $1021-4$.

Hakem R, Hakem A, Duncan GS, Henderson JT, Woo M, Soengas MS, Elia A, de la Pompa JL, Kagi D, Khoo W et al. 1998 Differential requirement for caspase 9 in apoptotic pathways in vivo. Cell 94 339-352.

Haywood M, Spaliviero J, Jimemez M, King NJ, Handelsman DJ \& Allan CM 2003 Sertoli and germ cell development in hypogonadal (hpg) mice expressing transgenic follicle-stimulating hormone alone or in combination with testosterone. Endocrinology 144 509-517.

Heckert LL \& Griswold MD 1991 Expression of follicle-stimulating hormone receptor mRNA in rat testes and Sertoli cells. Molecular Endocrinology $\mathbf{5}$ 670-677.

Heckert LL \& Griswold MD 2002 The expression of the follicle-stimulating hormone receptor in spermatogenesis. Recent Progress in Hormone Research 57 129-148.

Hengartner MO 2000 The biochemistry of apoptosis. Nature 407 770-776.

Henriksén K, Hakovirta H \& Parvinen M 1995 In-situ quantification of stagespecific apoptosis in the rat seminiferous epithelium: effects of short-term experimental cryptorchidism. International Journal of Andrology 5 256-262.

Henriksen K, Kangasniemi M, Parvinen M, Kaipia A \& Hakovirta H 1996 In vitro, follicle-stimulating hormone prevents apoptosis and stimulates deoxyribonucleic acid synthesis in the rat seminiferous epithelium in a stage-specific fashion. Endocrinology 137 2141-2149.

Holdcraft RW \& Braun RE 2004 Hormonal regulation of spermatogenesis. International Journal of Andrology 27 335-342.

Honarpour N, Du C, Richardson JA, Hammer RE, Wang X \& Herz J 2000 Adult Apaf-1-deficient mice exhibit male infertility. Developmental Biology 218 248-258.

Kangasniemi M, Kaipia A, Toppari J, Perheentupa A, Huhtaniemi I \& Parvinen M 1990 Cellular regulation of follicle-stimulating hormone (FSH) binding in rat seminiferous tubules. Journal of Andrology 11 336-343.

Kierszenbaum AL \& Tres LL 2004 The acrosome-acroplaxome-manchette complex and the shaping of the spermatid head. Archives of Histology and Cytology 67 271-284.

Knudson CM, Tung KS, Tourtellotte WG, Brown GA \& Korsmeyer SJ 1995 Bax-deficient mice with lymphoid hyperplasia and male germ cell death. Science 270 96-99.

Krajewski S, Krajewska M, Ellerby LM, Welsh K, Xie Z, Deveraux QL, Salvesen GS, Bredesen DE, Rosenthal RE, Fiskum G et al. 1999 Release of caspase-9 from mitochondria during neuronal apoptosis and cerebral ischemia. PNAS 96 5752-5757.

de Kretser DM, Catt KJ \& Paulsen CA 1971 Studies on the in vitro testicular binding of iodinated luteinising hormone in rats. Endocrinology 88 332-337.

Krishnamurthy H, Danilovich N, Morales CR \& Sairam MR 2000 Qualitative and quantitative decline in spermatogenesis of the follicle-stimulating hormone receptor knockout (FORKO) mouse. Biology of Reproduction 62 1146-1159.

Kuida K, Haydar TF, Kuan CY, Gu Y, Taya C, Karasuyama H, Su MS, Rakic P \& Flavell RA 1998 Reduced apoptosis and cytochrome $c$-mediated caspase activation in mice lacking caspase 9. Cell 94 325-337.

Lee J, Richburg JH, Younkin SC \& Boekelheide K 1997 The Fas system is a key regulator of germ cell apoptosis in the testis. Endocrinology 138 2081-2088.

Li X, Traganos F, Melamed MR \& Darzynkiewicz Z 1995 Single-step procedure for labelling DNA strand breaks with fluorescein- or BODIPY-conjugated deoxynucleotides: detection of apoptosis and bromodeoxyuridine incorporation. Cytometry 20 172-180.

Lizama C, Alfaro I, Reyes JG \& Moreno RD 2007 Up-regulation of CD95 (Apo-1/Fas) is associated with spermatocyte apoptosis during the first round of spermatogenesis in the rat. Apoptosis 12 499-512.

Lockshin RA \& Zakeri Z 2004 Caspase-independent cell death? Oncogene $232766-2773$.

Louis BG \& Fritz IB 1979 Follicle-stimulating hormone and testosterone independently increase the production of androgen-binding protein by Sertoli cells in culture. Endocrinology 104 454-461.
Marathe GK, Shetty J \& Dighe RR 1995 Selective immunoneutralisation of luteinising hormone results in the apoptotic cell death of pachytene spermatocytes and spermatids in the rat testis. Endocrinology 3 705-709.

Marshall GR, Ramaswamy S \& Plant TM 2005 Independent proliferation of the pale type A spermatogonia in the adult rhesus monkey (Macaca mulatta). Biology of Reproduction 73 222-229.

Matthiesson KL, Stanton PG, O'Donnell L, Meachem SJ, Amory JK, Berger R, Bremner WJ \& McLachlan RI 2005 Effects of testosterone and levonorgestrel combined with a 5alpha-reductase inhibitor or GnRH antagonist on spermatogenesis and intratesticular steroid levels in normal men. Journal of Clinical Endocrinology and Metabolism $905647-5655$.

Matthiesson KL, McLachlan RI, O'Donnell L, Frydenberg M, Robertson DM, Stanton PG \& Meachem SJ 2006 The relative roles of follicle-stimulating hormone and luteinising hormone in maintaining spermatogonial maturation and spermiation in normal men. Journal of Clinical Endocrinology and Metabolism 91 3962-3969.

Mayer F, Honecker F, Looijenga LHJ \& Bokemeyer C 2003 Towards an understanding of the biological basis of response to cisplatin-based chemotheraphy in germ-cell tumours. Annals of Oncology 14 825-832.

McLachlan RI, Wreford NG, Tsonis C, De Kretser DM \& Robertson DM 1994 Testosterone effects on spermatogenesis in the gonadotrophinreleasing hormone-immunized rat. Biology of Reproduction 50 271-280.

McLachlan RI, Wreford NG, de Kretser DM \& Robertson DM 1995 The effects of recombinant follicle-stimulating hormone on the restoration of spermatogenesis in the gonadotrophin-releasing hormone-immunized adult rat. Endocrinology 136 4035-4043.

McLachlan RI, O'Donnell L, Meachem SJ, Stanton PG, de Kretser DM, Pratis K \& Robertson DM 2002a Identification of specific sites of hormonal regulation in spermatogenesis in rats, monkeys, and man. Recent Progress in Hormone Research 57 149-179.

McLachlan RI, O'Donnell L, Meachem SJ, Stanton PG, de K, Pratis K \& Robertson DM $2002 b$ Hormonal regulation of spermatogenesis in primates and man: insights for development of the male hormonal contraceptive. Journal of Andrology 23 149-162.

McLachlan RI, O'Donnell L, Stanton PG, Balourdos G, Frydenberg M, de Kretser DM \& Robertson DM 2002c Effects of testosterone plus medroxyprogesterone acetate on semen quality, reproductive hormones, and germ cell populations in normal young men. Journal of Clinical Endocrinology and Metabolism 87 546-556.

Meachem SJ, Wreford NG, Robertson DM \& McLachlan RI 1997 Androgen action on the restoration of spermatogenesis in adult rats: effects of human chorionic, testosterone and flutamide administration on germ cell number. International Journal of Andrology 20 70-79.

Meachem SJ, Wreford NG, Stanton PG, Robertson DM \& McLachlan RI 1998 Follicle-stimulating hormone is required for the initial phase of spermatogenic restoration in adult rats following gonadotrophin suppression. Journal of Andrology 19 725-735.

Meachem SJ, McLachlan RI, Stanton PG, Robertson DM \& Wreford NG 1999 FSH immunoneutralization acutely impairs spermatogonial development in normal adult rats. Journal of Andrology 20 756-762 discussion 755 .

Meachem S, von Schonfeldt V \& Schlatt S 2001 Spermatogonia: stem cells with a great perspective. Reproduction 121 825-834.

Meachem SJ, Stanton PG \& Schlatt S 2005a Follicle-stimulating hormone regulates both Sertoli cell and spermatogonial populations in the adult photoinhibited Djungarian hamster testis. Biology of Reproduction 72 1187-1193.

Meachem SJ, Ruwanpura SM, Ziolkowski J, Ague JM, Skinner MK \& Loveland KL $2005 b$ Developmentally distinct in vivo effects of FSH on proliferation and apoptosis during testis maturation. Journal of Endocrinology 186 429-446.

Meachem SJ, Schlatt S, Ruwanpura SM \& Stanton PG 2007 The effect of testosterone, dihydrotestosterone and estradiol on the re-initiation of spermatogenesis in the adult photoinhibited Djungarian hamster. Journal of Endocrinology 192 553-561. 
Meehan T, Schlatt S, O'Bryan MK, de Kretser DM \& Loveland KL 2000 Regulation of germ cell and Sertoli cell development by activin, follistatin, and FSH. Developmental Biology 220 225-237.

Meehan T, Loveland KL, de Kretser D, Cory S \& Print CG 2001 Developmental regulation of the bcl-2 family during spermatogenesis: insights into the sterility of bcl-w $-/-$ male mice. Cell Death and Differentiation 8 225-233.

Melino G, Knight RA \& Nicotera P 2005 How many ways to die? How many different models of cell death? Cell Death and Differentiation 2 1457-1462.

Mruk DD \& Cheng CY 2004 Sertoli-Sertoli and Sertoli-germ cell interactions and their significance in germ cell movement in the seminiferous epithelium during spermatogenesis. Endocrine Reviews 25 747-806.

Muffly KE, Nazian SJ \& Cameron DF 1994 Effects of follicle-stimulating hormone on the junction-related Sertoli cell cytoskeleton and daily sperm production in testosterone-treated hypophysectomized rats. Biology of Reproduction 51 158-166.

Nagata S 1997 Apoptosis by death factor. Cell 88 355-365.

Nagata S \& Golstein P 1995 The Fas death factor. Science 267 1449-1456.

Nakanishi Y \& Shiratsuchi A 2004 Phagocytic removal of apoptotic spermatogenic cells by Sertoli cells: mechanisms and consequences. Biological \& Pharmaceutical Bulletin 27 13-16.

Nandi S, Banerjee PP \& Zirkin BR 1999 Germ cell apoptosis in the testes of Sprague-Dawley rats following testosterone withdrawal by ethane 1,2-dimethanesulfonate administration: relationship to Fas? Biology of Reproduction 61 70-75.

Narisawa S, Hecht NB, Goldberg E, Boatright KM, Reed JC \& Millan JL 2002 Testis-specific cytochrome $c$-null mice produce functional sperm but undergo early testicular atrophy. Molecular and Cellular Biology 22 5554-5562.

O’Donnell L, McLachlan RI, Wreford NG, de Kretser DM \& Robertson DM 1996 Testosterone withdrawal promotes stage-specific detachment of round spermatids from the rat seminiferous epithelium. Biology of Reproduction 55 895-901.

O’Donnell L, Pratis K, Stanton PG, Robertson DM \& McLachlan RI 1999 Testosterone-dependent restoration of spermatogenesis in adult rats is impaired by a 5alpha-reductase inhibitor. Journal of Andrology 20 109-117.

O’Donnell L, Meachem SJ, Stanton PG \& McLachlan RI 2006 Endocrine regulation of spermatogenesis. In Physiology of Reproduction, pp 1017-1069. Ed. JD Neill. San Diego, CA: Elsevier.

Orth JM 1984 The role of follicle-stimulating hormone in controlling Sertoli cell proliferation in testes of fetal rats. Endocrinology 115 1248-1255.

Orth JM, Gunsalus GL \& Lamperti AA 1988 Evidence from Sertoli celldepleted rats indicates that spermatid number in adults depends on numbers of Sertoli cells produced during perinatal development. Endocrinology 122 787-794.

Orth JM, Jester WF, Li LH \& Laslett AL 2000 Gonocyte-Sertoli cell interactions during development of the neonatal rodent testis. Current Topics in Development Biology 50 103-124.

Ottenweller JE, Li MT, Giglio W, Anesetti R, Pogach LM \& Huang HF 2000 Alteration of follicle-stimulating hormone and testosterone regulation of messenger ribonucleic acid for Sertoli cell proteins in the rat during the acute phase of spinal cord injury. Biology of Reproduction 63 730-735.

Pareek TK, Joshi AR, Sanyal A \& Dighe RR 2007 Insights into male germ cell apoptosis due to depletion of gonadotrophins caused by GnRH antagonists. Apoptosis 12 1085-1100.

Parvinen M 1982 Regulation of the seminiferous epithelium. Endocrine Reviews 3 404-417.

Parvinen M, Marana R, Robertson DM, Hansson V \& Ritszen EM 1980 Functional cycle of rat Sertoli cells: differential binding and action of follicle-stimulating hormone at various stages of the spermatogenic cycle. In Testicular Development, Structure and Function, pp 425-432. Eds A Steinberger \& E Steinberger. New York: Raven Press.

Pentikainen V, Erkkila K \& Dunkel L 1999 Fas regulates germ cell apoptosis in the human testis in vitro. American Journal of Physiology 276 E310-E316.
Print CG, Loveland KL, Gibson L, Meehan T, Stylianou A, Wreford N, de Kretser D, Metcalf D, Kontgen F, Adams JM et al. 1998 Apoptosis regulator bcl-w is essential for spermatogenesis but appears otherwise redundant. PNAS 95 12424-12431.

Riedl SJ \& Shi Y 2004 Molecular mechanisms of caspase regulation during apoptosis. Nature Reviews. Molecular Cell Biology 5 897-907.

Rodriguez I, Ody C, Araki K, Garcia I \& Vassalli P 1997 An early and massive wave of germinal cell apoptosis is required for the development of functional spermatogenesis. EMBO Journal 16 2262-2270.

Rodriguez JM, Glozak MA, Ma Y \& Cress WD 2006 Bok, Bcl-2-related ovarian killer, is cell cycle-regulated and sensitizes to stress-induced apoptosis. Journal of Biological Chemistry 281 22729-22735.

de Rooij DG 2001 Proliferation and differentiation of spermatogonial stem cells. Reproduction 121 347-354.

Ross AJ, Waymire KG, Moss JE, Parlow AF, Skinner MK, Russell LD \& MacGregor GR 1998 Testicular degeneration in Bclw-deficient mice. Nature Genetics 18 251-256.

Russell LD, Corbin TJ, Borg KE, De França LR, Grasso P \& Bartke A 1993 Recombinant human follicle-stimulating hormone is capable of exerting a biological effect in the adult hypophysectomized rat by reducing the numbers of degenerating germ cells. Endocrinology 133 2062-2070.

Russell LD, Chiarini-Garcia H, Korsmeyer SJ \& Knudson CM 2002 Bax-dependent spermatogonia apoptosis is required for testicular development and spermatogenesis. Biology of Reproduction 66 950-958.

Ruwanpura SM, McLachlan RI, Stanton PG \& Meachem SJ 2008a Follicle-stimulating hormone affects spermatogonial survival by regulating the intrinsic apoptotic pathway in adult rats. Biology of Reproduction 78 705-713.

Ruwanpura SM, McLachlan RI, Stanton PG, Loveland KL \& Meachem SJ $2008 b$ Pathways involved in testicular germ cell apoptosis in immature rats after FSH suppression. Journal of Endocrinology 197 35-43.

Ruwanpura SM, McLachlan RI, Mattheisson KL \& Meachem SJ 2008c Gonadotrophins regulate germ cell survival not proliferation, in normal adult men. Human Reproduction 23 403-411.

Sairam MR \& Krishnamurthy H 2001 The role of follicle-stimulating hormone in spermatogenesis: lessons from knockout animal models. Archives of Medical Research 32 601-608.

Saito K, O’Donnell L, McLachlan RI \& Robertson DM 2000 Spermiation failure is a major contributor to early spermatogenic suppression caused by hormone withdrawal in adult rats. Endocrinology 141 2779-2785.

Scaffidi C, Schmitz I, Zha J, Korsmeyer SJ, Krammer PH \& Peter ME 1999 Differential modulation of apoptosis sensitivity in CD95 type I and type II cells. Journal of Biological Chemistry 274 22532-22538.

Scobey M, Bertera S, Somers J, Watkins S, Zeleznik A \& Walker W 2001 Delivery of a cyclic adenosine $3^{\prime}, 5^{\prime}$-monophosphate response element-binding protein (creb) mutant to seminiferous tubules results in impaired spermatogenesis. Endocrinology 142 948-954.

Scott HM, Hutchison GR, Mahood IK, Hallmark N, Welsh M, De Gendt K, Verhoeven G, O'Shaughnessy P \& Sharpe RM 2007 Role of androgens in fetal testis development and dysgenesis. Endocrinology 148 2027-2036.

Shaha C 2007 Modulators of spermatogenic cell survival. Society of Reproduction and Fertility 63 173-186.

Shang Y, Myers M \& Brown M 2002 Formation of the androgen receptor transcription complex. Molecular Cell 9 601-610.

Sharpe RM, McKinnell C, Kivlin C \& Fisher JS 2003 Proliferation and functional maturation of Sertoli cells, and their relevance to disorders of testis function in adulthood. Reproduction 125 769-784.

Shetty G, Wilson G, Huhtaniemi I, Boettger-Tong H \& Meistrich ML 2001 Testosterone inhibits spermatogonial differentiation in juvenile spermatogonial depletion mice. Endocrinology 142 2789-2795.

Shi Y 2002 Mechanisms of caspase activation and inhibition during apoptosis. Molecular Cell 9 459-470.

Show MD, Folmer JS, Anway MD \& Zirkin BR 2004 Testicular expression and distribution of the rat bcl2 modifying factor in response to reduced intratesticular testosterone. Biology of Reproduction 70 1153-1161.

Silva FR, Leite LD \& Wassermann GF 2002 Rapid signal transduction in Sertoli cells. European Journal of Endocrinology 147 425-433. 
Simoni M, Gromoll J \& Nieschlag E 1997 The follicle-stimulating hormone receptor: biochemistry, molecular biology, physiology, and pathophysiology. Endocrine Reviews 18 739-773.

Simorangkir DR, Marshall GR, Ehmcke J, Schlatt S \& Plant TM 2005 Prepubertal expansion of dark and pale type A spermatogonia in the rhesus monkey (Macaca mulatta) results from proliferation during infantile and juvenile development in a relatively gonadotropin independent manner. Biology of Reproduction 73 1109-1115.

Singh J \& Handelsman DJ 1996 Neonatal administration of FSH increases Sertoli cell numbers and spermatogenesis in gonadotrophin-deficient ( $h p g)$ mice. Journal of Endocrinology 151 37-48.

Singh J, O'Neill C \& Handelsman DJ 1995 Induction of spermatogenesis by androgens in gonadotrophin-deficient $(h p g)$ mice. Endocrinology 136 5311-5321.

Sinha-Hikim AP \& Swerdloff RS 1995 Temporal and stage-specific effects of recombinant human follicle-stimulating hormone on the maintenance of spermatogenesis in gonadotrophin-releasing hormone antagonist-treated rat. Endocrinology 136 253-261.

Sinha-Hikim AP \& Swerdloff RS 1999 Hormonal and genetic control of germ cell apoptosis in the testis. Reviews of Reproduction 4 38-47.

Sluka P, O'Donnell L, Bartles JR \& Stanton PG 2006 FSH regulates the formation of adherens junctions and ectoplasmic specialisations between rat Sertoli cells in vitro and in vivo. Journal of Endocrinology 189 381-395.

Sugihara A, Saiki S, Tsuji M, Tsujimura T, Nakata Y, Kubota A, Kotake T \& Terada N 1997 Expression of Fas and Fas ligand in the testes and testicular germ cell tumors: an immunohistochemical study. Anticancer Research 17 3861-3865.

Tapanainen JS, Tilly JL, Vihko KK \& Hsueh AJ 1993 Hormonal control of apoptotic cell death in the testis: gonadotrophins and androgens as testicular cell survival factors. Molecular Endocrinology 7 643-650.

Tarulli GA, Stanton PG, Lerchl A \& Meachem SJ 2006 Adult Sertoli cells are not terminally differentiated in the Djungarian hamster: effect of FSH on proliferation and junction protein organization. Biology of Reproduction $\mathbf{7 4}$ 798-806.

Tesarik J, Guido M, Mendoza C \& Greco E 1998 Human spermatogenesis in vitro: respective effects of follicle-stimulating hormone and testosterone on meiosis, spermiogenesis, and Sertoli cell apoptosis. Journal of Clinical Endocrinology and Metabolism 83 4467-4473.

Tesarik J, Martinez F, Rienzi L, Iacobelli M, Ubaldi F, Mendoza C \& Greco E 2002 In-vitro effects of FSH and testosterone withdrawal on caspase activation and DNA fragmentation in different cell types of human seminiferous epithelium. Human Reproduction 17 1811-1819.

Vera Y, Erkkila K, Wang C, Nunez C, Kyttanen S, Lue Y, Dunkel L, Swerdloff RS \& Sinha Hikim AP 2006 Involvement of p38 mitogen-activated protein kinase and inducible nitric oxide synthase in apoptotic signalling of murine and human male germ cells after hormone deprivation. Molecular Endocrinology 20 1597-1609.

Verhoeven G \& Cailleau J 1988 Follicle-stimulating hormone and androgens increase the concentration of the androgen receptor in Sertoli cells. Endocrinology 122 1541-1550.

Vihko KK, LaPolt PS, Nishimori K \& Hsueh AJ 1991 Stimulatory effects of recombinant follicle-stimulating hormone on Leydig cell function and spermatogenesis in immature hypophysectomized rats. Endocrinology 129 1926-1932.

Wahlstrom T, Huhtaniemi I, Hovatta O \& Seppala M 1983 Localization of luteinising hormone, follicle-stimulating hormone, prolactin, and their receptors in human and rat testis using immunohistochemistry and radio receptor assay. Journal of Clinical Endocrinology and Metabolism 57 825-830.

Walker WH 2003 Nongenomic actions of androgen in Sertoli cells. Current Topics in Development Biology 56 25-53.
Walker WH \& Cheng J 2005 FSH and testosterone signaling in Sertoli cells. Reproduction 130 15-28.

West AP, Sharpe RM \& Saunders PT 1994 Differential regulation of cyclic adenosine $3^{\prime}, 5^{\prime}$-monophosphate (cAMP) response element-binding protein and cAMP response element modulator messenger ribonucleic acid transcripts by follicle-stimulating hormone and androgen in the adult rat testis. Biology of Reproduction $\mathbf{5 0} 869-881$.

Wolgemuth DJ, Laurion E \& Lele KM 2002 Regulation of the mitotic and meiotic cell cycles in the male germ line. Recent Progress in Hormone Research 57 75-101.

Wong CH, Xia W, Lee NP, Mruk DD, Lee WM \& Cheng CY 2005 Regulation of ectoplasmic specialization dynamics in the seminiferous epithelium by focal adhesion-associated proteins in testosterone-suppressed rat testes. Endocrinology 146 1192-1204.

Woolveridge I, de Boer-Brouwer M, Taylor MF, Teerds KJ, Wu FC \& Morris ID 1999 Apoptosis in the rat spermatogenic epithelium following androgen withdrawal: changes in apoptosis-related genes. Biology of Reproduction 60 461-470.

Wreford NG, Rajendra Kumar T, Matzuk MM \& de Kretser DM 2001 Analysis of the testicular phenotype of the follicle-stimulating hormone beta-subunit knockout and the activin type II receptor knockout mice by stereological analysis. Endocrinology 142 2916-2920.

Yagi M, Takenaka M, Suzuki K \& Suzuki H 2007 Reduced mitotic activity and increased apoptosis of fetal Sertoli cells in rat hypogonadic (hgn/hgn) testes. Journal of Reproduction and Development 53 581-589.

Yan W, Samson M, Jegou B \& Toppari J 2000 Bcl-w forms complexes with $\mathrm{Bax}$ and $\mathrm{Bak}$, and elevated ratios of $\mathrm{Bax} / \mathrm{Bcl}-\mathrm{w}$ and $\mathrm{Bak} / \mathrm{Bcl}-\mathrm{w}$ correspond to spermatogonial and spermatocyte apoptosis in the testis. Molecular Endocrinology 14 682-699.

Zhang ZH, Zhou XC, Wei P, Hu ZY \& Liu YX 2003 Expression of Bcl-2 and Bax in rhesus monkey testis during germ cell apoptosis induced by testosterone undecanoate. Archives of Andrology 49 439-447.

Zhengwei Y, Wreford NG, Royce P, de Kretser DM \& McLachlan RI 1998 a Stereological evaluation of human spermatogenesis after suppression by testosterone treatment: heterogeneous pattern of spermatogenic impairment. Journal of Clinical Endocrinology and Metabolism 83 1284-1291.

Zhengwei Y, Wreford NG, Schlatt S, Weinbauer GF, Nieschlag E \& McLachlan RI $1998 b$ Acute and specific impairment of spermatogonial development by $\mathrm{GnRH}$ antagonist-induced withdrawal in the adult macaque (Macaca fascicularis). Journal of Reproduction and Fertility 112 139-147.

Zhou XC, Wei P, Hu ZY, Gao F, Zhou RJ \& Liu YX 2001 Role of Fas/FasL genes in azoospermia or oligozoospermia induced by testosterone undecanoate in rhesus monkey. Acta Pharmacologica Sinica 22 1028-1033.

Zivkovic D \& Hadziselimovic F 2009 Development of Sertoli cells during mini-puberty in normal and cryptorchid testes. Urologia Internationalis $\mathbf{8 2}$ 89-91.

Zou H, Henzel WJ, Liu X, Lutschg A \& Wang X 1997 Apaf-1, a human protein homologous to C. elegans CED-4, participates in cytochrome c-dependent activation of caspase-3. Cell $90405-413$.
Received in final form 23 January 2010
Accepted 9 February 2010
Made available online as an Accepted Preprint 9 February 2010 